\title{
Descriptive Analysis of Vaughan Systems, Assets and Pitfalls of an Audiolingual Method
}

\author{
Betsabé Navarro Romero \\ Universidad de Santiago de Compostela
}

Received: 22 November 2011 / Accepted: 14 June 2012

ISSN: $1697-7467$

\begin{abstract}
This article explores the advantages and disadvantages of English language immersion courses, subsidized by the Spanish Ministry of Education and organized by the International University Menendez Pelayo, which hires the services of the American company Vaughan Systems. These immersion courses, called "Immersion for Verbal Agility", follow the "Vaughan Method" - a language learning methodology based, according to the author, on the well-known Audiolingual and Grammar Translation methods. The present study, based on observation and participation in one of the mentioned intensive courses, analyses the assets and pitfalls of what it is now a traditional language teaching method, providing a theoretical discussion on Second Language Acquisition and a brief review of the corresponding second language teaching methods.

Keywords: Ministry of Education, Vaughan Systems, Audiolingual method, Grammar Translation method, Second Language Acquisition, Second/Foreign Language Learning.
\end{abstract}

Análisis descriptivo de Vaughan Systems: ventajas y desventajas de un método audiolingual

RESUMEN: El presente artículo explora las ventajas y desventajas de los Cursos de Inmersión Lingüística subvencionados por el Ministerio de Educación, impartidos en la Universidad Internacional Menéndez Pelayo, y organizados por la compañía norteamericana Vaughan Systems. Estos cursos de inmersión, llamados Cursos de "Verbal Agility" o fluidez verbal, siguen lo que han llamado Método Vaughan, una metodología de enseñanza del Inglés que se basa, según el autor, en el conocido método Audiolingual, y el método de Gramática Traducción. El presente estudio, basado en la observación y participación en uno de los mencionados cursos, analiza los beneficios y los obstáculos de lo que ahora es un método de enseñanza tradicional, aportando una discusión teórica sobre la Adquisición de la Segunda Lengua y un breve resumen de los correspondientes métodos de enseñanza de segundas lenguas.

Palabras Clave: Ministerio de Educación, Vaughan Systems, Método Audiolingual, Método Gramática Traducción, Enseñanza, Aprendizaje, Adquisición de Segunda Lengua, Aprendizaje de Segundas Lenguas.

\section{INTRODUCTION: VAUGHAN SYSTEMS AND THE MINISTRY OF EDUCATION}

The Spanish Ministry of Education, in its attempt to promote young people's education, is aware of their need to learn a foreign language to facilitate their future professional career and integrate them into the labour market. At present, the Ministry of Education organises different education programmes for different students' profiles and at different levels, and 
provides the economic support to help students and their families face the costs of these programmes (BOE 24 May 2011). Moreover, the Council of Europe's aim to promote foreign language acquisition among European citizens with measures such as the Common European Framework of Reference (CEFR) and the European Language Portfolio (ELP), has led the Spanish Ministry of Education to organize language learning programmes and thus favour "multilingualism, cultural diversity and mobility in Europe" (BOE 24 May 2011).

Among the different initiatives, the Ministry of Education offers English language immersion courses organized by the International University Menendez Pelayo (UIMP), aimed at those University students who already have a theoretical and grammatical knowledge of the language but who have not had the opportunity of using this "oral and communicative skill” intensively (BOE 24 May 2011) ${ }^{1}$.

In this context, Vaughan Systems is regularly hired by the International University Menendez Pelayo in order to teach these language courses. Vaughan has been teaching English in Spain since the late 1970s with what they called "Vaughan Methodology". It is interesting to note that information about the teaching methodology can hardly be found on their website. Emphasis is made on the effectiveness of the method, on dynamic and creative lessons with a focus on conversation, indirect translations, sentence building, and repetition of questions and answers to promote the student's success and fluency in oral communication ("FAQs" Grupovaughan.com). Although it is not explicitly mentioned, this methodology corresponds with the traditional Audiolingual method in some aspects, and with the Grammar Translation method in others, but it is renamed the "Vaughan Method" in order to give a brand identity to the company's teaching methodology (Grupovaughan.com).

In this article the author provides an analysis of the Vaughan method, within the framework of the Audiolingual and Grammar Translation methods. The aim is to raise teachers' awareness of the advantages and drawbacks of this well known learning method, which although is considered outmoded by the more recent Communicative Language Teaching (CLT) approaches, it is still applied today by commercial companies in their goal of teaching English as a foreign language. We will evaluate the effectiveness - or lack thereof -, of the Vaughan method, the assets and pitfalls of a systematic and repetitive technique and its outcome in students' immediate learning. With this aim in mind, the author - observer and participant in one of these courses - will provide a description of the lessons, with sample activities, drills, lesson structure, and teachers' method of assessment. Subsequently, an analysis will be carried out with a review of the theoretical methodologies in which Vaughan courses are based, examining the advantages and disadvantages of the

${ }^{1}$ From 1970s onwards, the International University Menendez Pelayo (UIMP) has offered all kinds of courses in different fields of study such as Social Sciences, Humanistic Sciences (e.g. Social Anthropology, Psychology...), Technological and Experimental sciences, and they have also organized cultural and social activities such as Music, Theatre, and Poetry ("Historia" Uimp.es). Today UIMP offers Postgraduate courses, as well as Language courses, either Spanish Language and Culture courses for speakers of other languages, Training Courses for Teachers of Spanish as a Foreign Language, and English Language Immersion courses for students (Uimp.es) who are subsidized by the Ministry of Education and taught by the American company Vaughan Systems. 
Audiolingual and Grammar translation methods, and comparing them with the latest trends of the CLT approaches. Additionally, the author will make reference to Noam Chomsky's theory of language acquisition in order to analyse in depth the effectiveness of the Vaughan System in terms of Second Language Acquisition Theories. It is important to acknowledge that this analysis will exclusively be made upon present observation and upon the students' immediate reactions: no long-term analysis of the learning effects was carried out, leaving this as a future research activity.

\section{RESEARCH METHODOLOGY: METHODS AND TECHNIQUES}

The following analysis is based on the observation of one of the UIMP courses which took place in Barcelona from 1st to 5th August 2011. The author being a registered student during the course, observation, notes and analysis of the classes will constitute the materials to be analysed in this article. There will firstly be a description of the organization of the course, duration, timetable, lesson procedures, teaching methodology and final assessment. Examples of class activities will be provided, explaining their didactic purpose and their effect on the students. These examples will be used to analyse the most immediate and instant effects of the teaching system.

Firstly, it is necessary to mention the organization and structure of the UIMP courses. They always last five days, from Monday to Friday, in what is called a "weekly residential programme" ("English Agility" Uimp.es) - students are accommodated in a student residence close to their classrooms to make the immersion programme easier to realize. They have an intensive timetable, from 9.00 to 18.00 , including breaks, making a total of 40 schooling hours a week. Students have 3 lessons a day: Grammar, Vocabulary and Public Speaking, each lesson lasting two and a half hours. During breaks, mealtimes, free time and evening activities, teachers and language assistants, who are all native English speakers, accompany the students in order to elicit conversation in the target language. As such, emphasis is given to oral communication throughout the whole course, not only in class but also during the students' spare time. The aim of the crash course is that students end up speaking English with considerable fluency after one week, or as the methodology is called, "Immersion for Verbal Agility", which is designed to manage an oral competence in different contexts such as debates, interviews and oral presentations, by learning different strategies and procedures in order to gain fluency and communicative efficiency ("English Agility" Uimp.es). This is achieved by an emphasis on grammatical correctness, using constant drills, instant correction of every single mistake, and non-stop student participation. Eventually, no Spanish or mother tongue speaking is allowed.

The actual process starts at home when students complete a multiple choice test online to grade their level of English, since a minimum knowledge of the language is required in order to attend the course. The first day of the course, a similar test is given to students in class, and an oral interview takes place with the teacher to verify that their knowledge corresponds with the written test. However, it is necessary to point out that the multiple choice test focuses mainly on accuracy of grammar issues (prepositions and verbs), vocabulary and 
general speaking expressions. Moreover, the interview is not a communicative conversation, but follows an isolated and out of context question-answer model, to check that the student is able to restructure sentences by changing key words or modifying verbs. There is no actual need to understand the meaning of the questions themselves; the student is only required to have grammatical and structural knowledge of the language. In this respect, although the course is supposedly aimed at improving oral skills, the initial evaluation seems to be more oriented to grammatical structures.

\title{
Table 1. Initial Oral Test Sample Questions
}

\author{
Initial Oral test Sample Questions: \\ $\mathrm{T}$ : When's your birthday? \\ S: My birthday is on the first of May. \\ T: Have you ever been given the opportunity to go to Australia? \\ S: No, I have never been given the opportunity to go to Australia.
}

Finally, in accordance with their test results, students are organized in four levels (Basic, Intermediate 1, Intermediate 2, and Advance, corresponding with A2, B1, B2, and $\mathrm{C} 1$ of CEFR). Nevertheless, it is essential to mention again that the simplicity of grammar issues in the test does not correspond with level $\mathrm{C} 1$ in CEFR. Furthermore, as we will see later in the description of the classes, the vocabulary and grammatical issues do not correspond with an Advance level; a B2 might be more accurate. Here are some examples of the questions of the initial test:

Table 2. Initial Multiple Choice Test. Sample Questions

\section{Sample questions: Test 1}

1) What day is after Tuesday?
a) Friday
b) Tuesday
c) Thursday
d) Wednesday

2) What's the date today?

a) It's the January 3rd

b) It's the $3^{\text {rd }}$ of January

c) It's January the 3

d) It's $3^{\text {rd }}$ of January

3) I don't like winter. And you?

a) I don't like winter neither

b) I don't like winter either

c) I neither like winter

d) I don't like winter too

4) Jeremy is in prison because he a car 
When the test is completed, students are reorganized in small classes according to their level. Every class has an average of five students, which would be an ideal situation to give every student the opportunity to use the language and elicit student talk.

In every grammar class the teacher focuses on a specific grammatical issue to be learnt. This could be a particular verb tense (e.g. conditional verb forms, past perfect tense, past simple or modal verbs); a specific expression (e.g. "as long as", "provided that", "to be willing to", "have trouble + gerund"), question tags, or negative infinitives. The chosen element to be learned in the lesson is introduced without warming up activities; repetition and drills are introduced from the very beginning and they last for the whole lesson. Therefore, the same grammatical structure is constantly repeated orally by every student, one at a time, with the aim to integrate a particular structure and produce an automatic response from the student, so that after a while, the student is able to "fluently" produce the chosen grammatical scheme. It is interesting to note that the drills - question-answer schemes, restructuring sentences - have no communicative purpose; on many occasions the questions are meaningless and the answers are predictable. The students have to make a huge effort to remember long sentences which have to be repeated with no single mistake; consequently the emphasis is normally made on memory, instead of meaning and even structure. During the last ten minutes of the class, as a closure activity the teacher again revises the structures studied in class to check the students can reproduce them at once without a single mistake. Mistakes are not allowed, and the teacher's aim is to achieve the perfect production of a sentence; if the student makes a mistake, the teacher interrupts the student's production to correct them. Some examples of the drills that we can find in these classes are:

Table 3: Drills

\section{Drills:}

"Ask her if she enjoys living in Spain": "Do you enjoy living in Spain?"

"Ask her if she goes swimming every week": "Do you go swimming every week?"

"How often do you go fishing?" "I occasionally go fishing"

"How often do you have breakfast?" "I normally have breakfast three times a day"

"Did you get married last year?" "No, I didn't get married last year"

"Did you get dirty when you fell in a puddle?" "No, I didn't get dirty when I fell in a puddle".

"I'll go there only if you come with me": "As long as you come with me, I'll go there".

"Is it true or not that the more you eat, the fatter you get?": It's true that the more you eat the fatter you get"

"Is it true or not that the longer you live the later you die?": It's true that the longer you live the later you die". 
Finally, some grammar translation activities are also carried out in class. The teacher provides a sentence in Spanish and the students have to translate it into English with no single mistake. The aim is to practice verb tenses, prepositions, common expressions, etc:

\title{
Table 4: Translation Exercises
}

\author{
Translation exercises: \\ "Lo haremos a pesar de que no hay dinero": "We'll do it despite the fact that there isn't any money" \\ "Lo hare a pesar de todo": "I'll do it in spite of everything" \\ "Lo harán siempre que los respaldes": "They’ll do it as long as you back them up"
}

Regarding corrections in class, it should be noted that every single mistake is corrected at once; even synonyms are not allowed to be used in sentence construction - the students need to rebuild the structure using the same words. In this way, no creativity is allowed, which shows that the focus is on form rather than meaning:

\section{Table 5: Accuracy and Corrections}



In this respect, if the student wants to ask something or does not understand anything, it seems there is no time for questions because drilling and repetition are time consuming, exhausting, and repetitive. It is therefore very difficult to find the adequate moment to interrupt the machine-like system in order to clarify doubts or ask questions.

In the Vocabulary class, a deductive system is again used to teach vocabulary items. With no introductory activities, a topic is chosen for the day ("the internet", "advertising and marketing", "natural disasters", "law and crime", phrasal verbs, idioms) and the list of vocabulary is presented on the blackboard with an explanation, in English, of the unknown words. After the presentation, the teacher asks the students to say some sentences using the new vocabulary to check that they are using it adequately, and again, for homework to write sentences or a brief story to practice the correct use of the new words. Immediately, a new topic is presented, and the same pattern of class structure follows. At the end of the class, in order to wrap up the contents of the day, the teacher asks the students to list the words they remember, again as a memory practice. This system corresponds with the so-called Presentation, Practice and Production (PPP) pattern. 


\section{Table 6: Vocabulary Lists}



Finally, in the Public Speaking class, the main aim is to prepare students for public presentations, to learn to organize time and content in advance, but also learn how to improvise and react on time under a "stressful" situation. Help is also given to students; some instructions are given for preparation, as well as a lot of real practice in class. Throughout the week, students have to improvise short presentations in each day's lesson, and prepare longer presentations as homework for the following day.

\section{Table 7: Tips of Advice for Public Speaking sessions}

\section{Tips of Advice for Public Speaking sessions:}

1) Establish a good rapport with the audience

2) Catch their attention so that they listen to you

3) Plan and organize your ideas in advance, use an interesting topic and start with a punchy statement.

4) Control your body language, remember eye contact is essential.

5) Learn some key sentences/linkers, they will help you to structure your talk ("that's beyond my brief for today..."/ you may perhaps be thinking...." " this is not to overlook this point...").

The presentations in the advance level vary between 2 and 15 minutes, but in lower levels vary between 2 and 7, or 10, minutes. Among the activities that elicit student talking are role plays, debates, interviews, providing personal information, talking about a topic the students were interested in, and games (specifically, taboo games: defining ideas or objects without mentioning a "forbidden word").

Public Speaking classes are the most creative and free-style classes of the course. Students are allowed to be imaginative and to express themselves, to talk about their interests and to elaborate sentences freely, without constant correction, or without being forced to use a particular structure. Therefore, presentations become the only kind of activity in the course which is more communicative, focused on content and meaning. 
Overall, we can confirm that all three classes (Grammar, Vocabulary and Public Speaking) lack a full structure, with no warm-up activities or closing exercises. Presentation, practice and production - in the form of repetition - shape everyday lessons.

Finally, on the last day of the week students face the longest oral presentation and a final test. The test is very similar to the introductory test, using multiple choice questions to check how much the students have learned. However, we should note that on many occasions the questions in the test do not fit the vocabulary or grammar items studied during the week; it seems to be a test chosen at random, which makes the test results not conclusive or meaningful for the learning process. With regards to the evaluation method for the final presentation, it is necessary to mention that the teacher focuses on content (thesis statement, plan, structure, vocabulary and conclusion), delivery (pace, time keeping, posture, eye contact, smiling, hand gestures, use of visual aids and notes), and the ability to handle questions.

\section{Students' immediate Reactions to Vaughan Systems}

In terms of Second Language Acquisition, the method described above has advantages and drawbacks for the students' learning. This Audiolingual and Grammar Translation-based method focused on constant drills, repetitions and structure building statements, actually promotes the acquisition of fluency in students after one intensive week being immersed in this course. After the systematic repetition and formation of linguistic habits the students are able to produce perfect grammatical sentences without mistakes and with considerable ease. The mechanization of structures has a positive effect on the students' fluency, and the apparent general feeling is that this method is actually effective and that the student is able to speak English after only one week of intense repetition. In addition, the strict demand of correct utterances by teachers makes the student polish their sentence construction and produce perfect grammatical sentences, increasing the students' feeling of linguistic proficiency. Notwithstanding, it is essential to point out that the effects of this method are essentially analysed in terms of the mere observation of the students' immediate reactions and the appreciation of the general atmosphere at the end of the course among the students, as no long-term evaluation of the method was carried out, and no tests or interviews were made to prove real long-term effects on the students. This remains as ground for future research. What I consider as pitfalls of the "Vaughan Method" or its undesirable results entail the immediate effects this method has on the students.

Therefore, the perception of the "negative" effects that this method causes is exposed as follows. First of all, carrying out repetitive drilling structures and sentences for so many hours over a whole week produces, on many occasions, boredom in the students. In fact, the students' concentration normally drops during drills because, firstly, there is no communicative need: questions and answers are completely detached from one another, there is no coherence or sense of discourse and therefore they get exhausted and bored. Secondly, the mechanization of structures makes the human brain systematize a particular statement without awareness and the ability to repeat it instinctively. In addition, when losing concentration, many students start daydreaming, and they are even able to answer the questions without understanding the content of the question because the only thing they need to do is "repeat". On many occasions they make many mistakes, not because they don't know the specific structure, but because they are tired and not attentive enough. 
Here we can refer to professor Michael Byram's critique of the Audiolingual method, in which he enumerates several pragmatic disadvantages of the method:

Learners became bored with drills and pattern practice; the move from repetition and closely guided re-use of learned structures to spontaneous re-use of those same structures was not clearly specified; contrastive analysis did not anticipate and eradicate all the errors learners made; materials and the method itself appeared to provide only for the first few years of learning, and not for intermediate and advanced learners. (Byram, 2000: 60).

In this respect, and according to a general appreciation of the students' feelings, fluency is actually achieved and experienced at the very end of the course. However, this conclusion is only drawn from general observation: Although analyses on the Audiolingual method have shown that on many occasions pattern practice and repetition produce short-term learning, scientific evidence has not been able to be elicited from the Vaughan Method for no tests were taken to consider its real long-term effects. This is left for future research on this specific method.

However, the evident lack of a communicative approach makes the whole system repetitive, systematic and exhausting for students. Some contradictions frustrate students when they are required to participate in class and there is, at the same time, a serious problem of motivation, since they cannot produce creative statements or communicate personal information. Students are only required to repeat the teachers' prompt sentences and structures. Additionally, the fact that all the teachers come from different countries, which would motivate students to learn about cultural diversity and promote cultural intercommunication, seems to be useless: the system does not allow the utilization of the advantages of having teachers with different accents and different nationalities. With this systematic and mathematical method there is no real use of the cultural and linguistic background of the native teachers.

Moreover, small classes, which would be an ideal situation to promote communicative learning and speaking, become - again - a missed opportunity, because all production is repetitive and uncreative. Initiative by students is not allowed; they are given the structures and the vocabulary to be repeated once and again, with no opportunity to discover meanings, to explore or to create.

Overall, there are many disadvantages to this system that, in fact, hinder effective and creative learning. The method promotes above all, tiredness and boredom.

\section{Theoretical discussion: SeCOnd language aCQUiSition AND LANGUage TEACHING METHODOLOGY}

To understand the cognitive processes that take place in Second Language Acquisition, so as to choose an appropriate methodology in the teaching of second or foreign languages, it is essential to make reference to one of the most authoritative voices on linguistics of the twentieth century: Noam Chomsky and his theory of Second Language Acquisition. Chomsky's theory explained that language acquisition is based on the later development of deep, uncons- 
cious and innate grammar rules that underlie all languages and all grammatical rules. This was the so-called Universal Grammar, which "consists of the sorts of grammatical categories and principles that are common to all languages" (O'Grady, 2005:184). Chomsky stated that children are born with this inner system, which allows them to learn a language:

The first fragments of generative grammar in the 1950s and 1960s showed, on the one hand, that the implicit knowledge of language was amenable to a precise study through models which had their roots in the theory of formal systems, primarily in the theory of recursive functions; on the other hand, they immediately underscored the fact that the intuitive linguistic knowledge that every speaker possesses, and which guides his linguistic behaviour, is a system of extraordinary complexity and richness. Every speaker implicitly masters a very detailed and precise system of formal procedures to assemble and interpret linguistic expressions. This system is constantly used, in an automatized and unconscious manner, to produce and understand novel sentences, a normal characteristic of ordinary language use. (Belletti and Rizzi, 2003: 5).

In this respect, language is understood as a "biological instinct" (Pinker, 1994). In other words, children learn to speak because they are born with that ability, because they bring unconscious and potential abilities that are developed as the child grows up and starts interacting with the world. Interaction, in this context, is a key concept to understand that learning takes place in an unconscious manner when a child communicates with the surrounding world through a particular language; hence that language is developed without instruction, without the need to be taught.

Expanding on Chomsky's above theory, other theorists, such as Patsy M. Lightbown and Nina Spada (2000), support and emphasize the important role of interaction in the learning process. As I have argued elsewhere, "this approach has been called 'social interactionism' and argues that language is developed as a result of a communicative exchange between the child and the environment" (Navarro, 2010: 119). Thus, it is important to focus on the key term "communicative exchange", which is classified as learning that takes place with interaction. More concretely, it takes place with communicative interaction: the child acquires a language when he or she is immersed in a communicative environment in which language and context, in this case, intertwine so as to create a meaningful communication, giving sense to words, intonation, and grammar.

In opposition to Chomsky's theory of language acquisition, it is common to find conductivist theories which explain language learning as a result of imitation and repetition of sample language: "Traditional behaviourists believed that language learning is the result of imitation, practice, feedback on success, and habit formation" (Lightbown and Spada, 2000: 9). This approach argues that learning takes place only after the formation of linguistic habits; language acquisition is understood as an integration of grammatical rules and vocabulary, this being a consequence of repetitive oral input and constant imitation (output), with the corresponding correction that shapes language in a perfect linguistic structure. However, it is essential to provide a counter-argument here, since there are critics who suggest that learning does not occur by mere imitation of sentences, since memory only reaches simple words, and not full sentences. Additionally, learners are creative beings who have the ability 
to produce sentences that they have never listened to before (Navarro, 2010: 119), which opposes the idea that the child only learns what he has previously been taught.

Finally, it is important to state that the child or the learner is naturally able to restructure their own production, to create a sentence in a different way if they are aware that they have made a mistake. As Chomsky defined it, "An essential property of language is that it provides the means for expressing indefinitely many thoughts and for reacting appropriately in an indefinite range of new situations" (Chomsky, 1976: 6). For Chomsky, this is the creative aspect of language. On the contrary, from the behaviourist perspective, the output should take place mechanically, fluently and perfectly uttered from the beginning, without any mistakes and according to a concrete grammatical structure, in order to be considered a valid and a native-like production.

In light of this theoretical background on Second Language Acquisition, it is important to analyse Vaughan Systems as following a behaviourist and conductivist approach to language learning. The Vaughan Method follows the theory that with constant repetition of sentences, grammatical structures and specific vocabulary, the adult learner rapidly acquires fluency. Drilling is the core pillar of this system; as we have previously seen, the student is subject to the repetition and restructuring of sentences to practice and integrate a particular grammatical issue. For example:

T: "Is it true or not that the more you eat, the fatter you get?"

$S$ : It's true that the more you eat the fatter you get"

T: "Is it true or not that the longer you live the later you die?"

$S$ : It's true that the longer you live the later you die".

Another important aspect to bear in mind is that this system is effective because the students are adult learners and they are able to analyse and memorise grammatical rules. They are firstly taught the structure and then, practice the structure with mechanical repetition without a context. The result in adult learners is the acquisition of an effective fluency when producing full sentences, with perfect linguistic structures and not a single mistake. Correction in this context is essential; any mistake results in the teacher asking the student to repeat the whole sentence until it is produced in "perfect" English.

In addition, what is more surprising is the fact that synonyms are not allowed in sentence repetition, giving the impression that they are also another type of mistake. This is to say, learners in their attempt to remember a long sentence sometimes use, unconsciously, a synonym of a given word, and as a result, they are corrected in order to utter the given word. Hence, it is inferred that the focus is on form, and not on meaning, and that linguistic creativity is not allowed:

\section{T: "Did you become a better writer?" \\ $S:$ "Yes, I improved" \\ T: "Yes, I became a better writer"}

As a significant drawback of this system, we need to highlight the fact that students actually have problems remembering the long sentences they are required to repeat and, as a consequence, make numerous mistakes. Therefore, a great effort is made to remember these 
long sentences word by word without making a single mistake, in terms of both vocabulary and grammatical structure. This exercise does not prove that the students have truly integrated the particular grammatical issue or not; it only serves to repeat a specific structure immediately. A need to evaluate these activities' effect on the students' long-term memory is necessary in order to assess the real effectiveness of this method. As I have mentioned above, this remains for future research.

However, and despite the lack of scientific evidence in the real effects of this particular method, general theories on memory and learning, especially studies on psycholinguistics, examine how memory works and where the relationship between memory and language learning sits. Experts such as Mick Randall have analysed how the different types of memory interrelate with the process of learning a language. On the one hand, "Associative Learning", defended by the behavourist philosophy, states that, "In general, work on learning new material has shown that the greater the number of repetitions, the stronger the learning" (Randall, 2007: 126). The aim is to create an association stimulus-response. Despite the fact that no tests were made to check the long-term effects of associative memory in the Vaughan Method, other case studies in the field and psycholinguistic theorists suggest that there are better results in memory through a dynamic and procedural learning, than through the repetition of systematic utterances. Manipulation of meaning is more effective than meaningless stimulus-response activities on a long-term basis (Stevick, 1976: 26) ${ }^{2}$. In this respect, Earl W. Stevick goes on to say that according to research and experiments, oral drills have evident advantages on the short-term memory, and only through an emotional or manipulative activity the retention of that linguistic "image" would take place in the long-term memory (Stevick, 1976: 76-77). Other studies on memory suggest that repetition actually fixes up to seven new items (words/sentences) on the short-term memory in every memory session, yet only some of these items will enter the long-term memory, which shows that other factors such as time, effort or attention pay a key role in "memorability" (Schwartz and Reisberg, 1991: 264-268). Future research needs to be carried out in order to evaluate if the Vaughan Method actually has long-term effects on memory.

On the other hand, and following Randall's distinction, we have the "Procedural Memory", which refers to the type of memory exercised in a kind of experiential learning: learning in action, or learning by doing. From this perspective, we could argue that communicative language teaching approaches understand that learning a language through communication requires this procedural memory, where interaction and meaning produce an unconscious experiential or procedural learning. With regards to interaction, it is true that in the Vaughan courses an interaction exists between the teacher and the learner. Yet, this interaction takes place in the form of drills: the teacher asks, the student responds, and therefore, there is no communicative interaction in the classroom, which is based on repetitive sentences with the focus on form, and not on meaning. Consequently, the students easily get bored.

\footnotetext{
${ }^{2}$ Earl W. Stevick mentions, in his book entitled Memory, Meaning and Method (1976), different experiments where researchers evidenced the real effects that certain instrumental, active and deductive activities had on memory, in comparison with a mere repetition of some particular linguistic units. These investigators used different groups of learners who were exposed to different kinds of stimuli and different activities in order to make them learn new words. The result of these studies was, broadly speaking, that the performance of those learners who went through more (mentally) dynamic activities was superior to those learners who were exposed to mere repetition (Stevick, 1976: 25-26).
} 
In an attempt to create an interactive and communicative atmosphere, there are some bilingual schools and other immersion programmes that promote a different kind of learning. Their main aim is to provide students with a meaningful context in which they can learn maths, science or music in English (in the case of bilingual schools), and any other kind of content in general immersion programmes ${ }^{3}$. Roy Lyster, in Learning and Teaching Language through Content (2007) explains the important role of immersion programmes in the acquisition of the second language. In such courses, the students have a greater amount of contact hours with the Second Language (L2) and the methodology used is focused on a more naturalistic and communicative approach to learning. Therefore, the quantity and quality of the input the students receive increase, which in turn has positive results on the acquisition of the new language.

Therefore, the greatest benefit of Vaughan Systems courses is the fact that they are crash courses in which the quantity of input is considerably higher than in the students' normal circumstances. In this respect, it is true that the amount of contact hours with the L2 has evident and positive results in students' learning. However, concerning the quality of input, it needs to be highlighted that drilling conveys a risk of boredom, and the systematisation of only some specific structures, limiting other different structural possibilities.

Finally, if we briefly recall traditional methods of language teaching, we cannot avoid mentioning the Audiolingual method and the Grammar Translation method as the methodological teaching sources on which the Vaughan Method is based. On the one hand, the Grammar Translation method focused on specific grammatical structures, specific vocabulary and specific translation exercises in order to practice the given linguistic issues. Such translation exercises are present in the Verbal Agility Courses (see table 1.4), when students are required to translate, orally, a particular sentence in order to practice a grammatical rule and the given vocabulary. However, a teaching method based mainly on translation entails some obstacles; Jeremy Harmer mentions the lack of natural language input to which students are exposed, and the consequent lack of natural output and real language that the students will be able to produce:

\begin{abstract}
A total concentration on grammar-translation stops students from getting the kind of natural language input that will help them acquire language (since they are always looking at L1 equivalents), and it fails to give them opportunities to activate their language knowledge. If they are always translating the language, they are not using the L2 for communication. The danger with Grammar-translation, in other words, is that it teaches people about language but doesn't really help them to communicate effectively with it. (Harmer, 2007:49)
\end{abstract}

On the other hand, regarding the Audiolingual method, we cannot but mention the "military" style with which drills are practiced by students participating in Vaughan Systems

\footnotetext{
${ }^{3}$ Immersion programmes are sometimes organised to teach English to children and work with them for about one week in a farm or any other educative and recreational atmosphere. In such contexts, students learn vocabulary (i.e. animals, food...); common speaking expressions and simple actions (i.e. "open your hand"). They normally take place in a communicative atmosphere, placing emphasis on meaning, not on form.
} 
courses. Students are given sentences to transform according to a specific pattern, or using a specific verb tense, but they are required to be repeated to memorise the structure, which resembles repetitive militarist behaviour (see table 1.3). This recalls the true origins in which this method was born. It is well-known that the Audiolingual method was a consequence of the need to instruct American soldiers in foreign languages after the entry of the United States into World War II. They needed translators and interpreters in a very short period of time so the government asked universities to design foreign language programmes for their soldiers (Richards and Rodgers, 1992: 44). This method, based on a behaviourist psychological theory, suggests that:

Language learning is simply a matter of imitation and habit formation. Children imitate the sounds and patterns which they hear around them and receive positive reinforcement (which could take the form of praise or just successful communication) for doing so. Thus encouraged by their environment, they continue to imitate and practice these sounds and patterns until they form "habits" of correct language use. (Lightbown and Spada, 1996: 1)

This traditional method received a lot of criticism by new teaching tendencies, arguing that this unnatural and systematic teaching approach deprived students from receiving and using real and natural language, and that learning was more than acquiring habits: students should be able to use and create their own personal communication. As Harmer comments:

Audio-lingualism (and behaviourism) lost popularity because commentators argued that language learning was far more subtle than just the formation of habits. For example, students are quickly able to produce their own combinations of words, whether or not they have heard them before [...] Methodologists were also concerned that in Audio-lingualism students were not exposed to real or realistic language, and were therefore unlikely to produce natural-sounding language themselves. (Harmer, 2007: 49)

From the 1970s onwards, a reaction against too much formal and structural instruction took place, and theorists pleaded for a more meaningful and contextualized learning. Here we can frame the Communicative Language Teaching approaches (CLT) which start prioritizing language in context and language in use, understanding language as a tool for communication:

The communicative approach in language teaching starts from a theory of language as communication. The goal of language teaching is to develop what Hymes (1972) referred to as "communicative competence" [...] Hymes held that such a view of linguistic theory was sterile, that linguistic theory needed to be seen as part of a more general theory incorporating communication and culture. (Richards and Rodgers, 1992: 69-70)

Despite the popularity that this approach has had in recent decades - being considered as the most successful approach to language teaching during the late twentieth and the early 
twenty-first centuries - we can now certify that traditional and condemned methods such as the Audiolingual and the Grammar Translation are presently used in private language schools and also currently subsidized by the Spanish Ministry of Education.

\section{Conclusions}

It is important to be critical of the teaching methodologies that are employed not only in private schools but also in courses that are subsidized by public investment; in this case, the Spanish Ministry of Education. Yet we need to be aware of both the advantages and disadvantages that these methods cause, so as to contribute with constructive criticism and, therefore, be conscious of the positive results that these teaching systems provide as well as those aspects that unfortunately fail to provide effective learning in our students.

In this article the author has given an accurate description of the courses subsidized by the Ministry of Education, and organized by the International University Menendez Pelayo, when hiring the services of the private company Vaughan Systems. The so-called "Vaughan Method" is an example, among many others, of the well-known Audiolingual and Grammar Translation methods and, as such, the author has emphasized the most immediate assets and pitfalls of its teaching methods.

On the one hand, although no later tests or interviews have been made to consider the effectiveness of this method on a long-term basis, we can highlight an evident and direct improvement in students' fluency and grammatical accuracy after an intensive week of drilling and sentence construction and reconstruction (this was the general perception among the students). The general feeling (according to observation) is that this method is undoubtedly effective, since they are able to speak fluently and feel confident when producing specific statements that have been practiced throughout the whole course. On the other hand, this method is evidently detrimental to students' motivation; they get easily bored, as they are subject to constant automatic repetitions. This ultimately decreases all the good potential that an immersion course like this could have if it was based on a more communicative and meaningful language learning process. Eventually, there is a future need to consider its real long-term effects by means of testing or interviewing the students time after the course has finished, which remains for later research.

\section{Works Cited}

Belletti, A. and Rizzi, L. (eds.) (2003). "Some Concepts and Issues in Linguistic Theory", in Chomsky, N., On Nature and Language. Cambridge: Cambridge University Press, 1-44.

Byram, M. (2000). "Audiolingual Method", in M. Byram, (ed.), Routledge Encyclopedia of Language Teaching and Learning. London/New York: Routledge, 58-60.

Chomsky, N. (1976). Aspects of the Theory of Syntax. Massachusetts: The Massachussets Institute of Technology Press.

Harmer, J. (2007). How to Teach English. Harlow: Pearson Education Limited. 
Lightbown, P. M., and Spada N. (2000). How Languages are Learned. Oxford: Oxford University Press.

- (1996). How Languages are Learned. Oxford: Oxford University Press.

Lyster, R. (2007). Learning and Teaching Languages through Content. Amsterdam: John Benjamins.

Navarro Romero, B. (2010). "Adquisición de la Primera y Segunda Lengua en Aprendientes en Edad Infantil y Adulta", in Philologica Urcitana, vol. 2: 115-128.

O'Grady, W. (2005). How Children Learn Language. Cambridge: Cambridge University Press.

Pinker, S. (1994). The Language Instinct. New York: William Morrow and Company.

Randall, M. (2007). Memory, Psychology and Second Language Learning. Amsterdam/Philadelphia: John Benjamins Publishing Company.

Richards, J. C., and T.S. Rodgers (1992). Approaches and Methods in Language Teaching: A Description and Analysis. Cambridge: Cambridge University Press.

Schwartz, B. and Daniel R. (1991). Learning and Memory. New York: W. W. Norton \& Company.

Stevick, E.W. (1976). Memory, Meaning and Method: Some Psychological Perspectives on Language Learning. Rowley: Newbury House. Institutional Documents and Organisations.

BOE (2011). "Orden EDU/1344/2011, on 24 May 2011". 9045. Number 123. Section III, p. 51662. http://www.boe.es/boe/dias/2011/05/24/pdfs/BOE-A-2011-9045.pdf. Web accessed 20 August 2011.

“English Agility UIMP”. Uimp.es. n.d. http://www.uimp.es/index.php?\&option=com content\&view=article\&id=454. Web accessed 20 August 2011.

"FAQs". Grupovaughan.com. n.d. http://www.vaughanradio.com/faqs. Web accessed 20 August 2011.

"Historia". Uimp.es. n.d. http://www.uimp.es/institucional/historia.html. Web accessed 20 August 2011. 